\title{
The Role of Management Accounting in the Era of "Internet Plus" in the Transformation and Promotion of the Accounting Industry
}

\author{
Manli Sun \\ Xi'an Peihua University, Xi'an, Shaanxi, China
}

Keywords: "Internet Plus"; management accounting; the transformation and promotion; data value

\begin{abstract}
Through the description of the background of the "Internet plus" era and the development of management accounting, this paper puts forward the roles and functions of the management accounting in the transformation and upgrading of the accounting industry. In this paper, a more profound understanding of the importance of management accounting is conductive to study and application of the management accounting.
\end{abstract}

\section{The Background of the "Internet Plus " Era and the Current Development of Management Accounting}

\subsection{The background of the "Internet plus" era.}

In fact, the "Internet plus" is the process of spreading and applying a whole set of information technology based on the Internet (including mobile Internet, cloud computing, large data technology, etc.) in all sectors of economic and social life.

Internet thinking is the most important symbol of our times. The combination of Internet and business organizations has spread all over the world. Internet plus traffic has emerged Didi Taxi, Internet plus finance has appeared balance treasure, Internet plus mall has appeared Tmall Mall, Internet plus tourism has appeared Ctrip. com, the Chinese online travel agency, Internet plus air ticket emerged Qunar, Internet plus map appeared Autonavi Navigation, the new industry derived from the development of the Internet has become a new industry that screws into our daily life quietly.

\subsection{Present Situation of Management Accounting.}

Management accounting (Management Accounting), also known as "analysis report accounting", a management term. In order to improve the economic efficiency of the enterprise, it is an accounting branch where the accountants process, collate and report anything through a series of special methods using the information provided by financial accounting and other information, so that the managers at all levels can plan and control the daily economic activities and help the decision-makers to make various specialized decisions.

With the digitalization, networking, intellectualization and standardization of the Accounting qualification certificate management, the level of accounting management has improved in many aspects. The traditional accounting can not meet the needs of the enterprise. In addition to various certification certificates, the accounting industry should pay more attention to the practical skills of the accountants. The traditional accountants who only can book, calculate, and send accounts can not adapt to the needs of the society in the new situation.Accounting is bound to be transformed into management accounting. In the next ten years, the talent structure of accounting industry will be fundamentally changed. Medium and low-level financial accountants will be replaced by managerial accountants. It is estimated that $60 \%$ of the financial accountants will be forced to be unemployment or change careers. Therefore, the traditional accounting should get out from the "financial accounting" in time and turn to "management accounting", which is the future development trend of the accounting industry. 


\section{The Function of Management Accounting in the Era of "Internet Plus" in the Transformation And Upgrading Of The Accounting Industry}

In the new times of Internet, traditional enterprises should use the thinking and spirit of the Internet to do management innovation, use management accounting to do meticulous analysis and the decision-making. We should make use of cloud computing and large data of Internet applications to promote interconnection and intercommunication both inside and outside of enterprises, and realize the reconstruction of enterprises with data. In order to realize the transformation of the accounting industry, we can realize the transformation of the accounting industry. If the accounting industry wants to reform smoothly, it must vigorously promote the construction of management accounting system to promote the transformation and upgrading of the entire accounting industry.

\subsection{Comprehensively Promoting The Construction Of Management Accounting System Is An Important Direction Of Accounting Reform And Development.}

Since the establishment of the market economy system, the accounting in China has been closely related to the financial accounting. The accounting reform and development have made remarkable achievements including:(1)accounting standards, internal control norms, accounting information and other accounting standards have been steadily and effectively implemented;(2)the construction of accounting personnel has achieved remarkable results;(3) The industry of Certified Public Accountants has developed vigorously;(4) the theoretical system of financial accounting with Chinese characteristics has taken shape initially, which have strongly supported the economic and social development.

However, for a long period of time,we put too much in our accounting standards construction, accounting academic research and accounting practice,and consider the external investors, the public and the external audits much more. The internal management decisions are not enough, the development of management accounting is lagging behind, and the abilities of the planning, decision-making and evaluation for the development of businesses do not well in the industrial structure adjustment.

Therefore, after the pain, the market only lets us realize that the overall promotion of the construction of the management accounting system is an inevitable choice to comply with the development of accounting science. It is the necessary measure to realize the self-transcendence and self-perfection of the Chinese characteristic accounting system, and is the key point to promote the transformation of accounting industry.

\subsection{The Analysis Model of Management Accounting Can Analyze Financial Data More Comprehensively.}

Accountants are exposed to a large amount of data every day, which conveys a lot of information, but it is useless if it is just a number of financial figures. Data is historical data, financial accounting generally can only answer the "what" and can not answer the "why".

However, for management accounting, a large number of hidden information needed by business operators in financial data can be excavated actively through the systematic analysis of the data of the enterprise. Of course, on the basis of financial accounting, it should be analyzed with statistical accounting, business accounting and other related data, and the meaning behind the data in your financial statements is seen. It is estimated and deduced deeply, objectively appraised, thus find out the gap with the colleagues, and make a guiding prediction for the future trend of the enterprise.

\subsection{Cloud Computing and Big Data Inject New Vitality and Connotation to the Development of Management Accounting, So that Accounting Can Realize the Function of Meticulous Management.}

In the times of Internet, traditional enterprises will not be replaced by Internet enterprises, but "Internet", the essence of enterprise management has not changed, it is also the management of personnel, property, production and supply, but the concept, mode, tools and methods of management have been revolutionized. Such as Financial Sharing Center model, cloud procurement, e-commerce, 
cloud manufacturing, cloud recruitment, cloud services of staff travel and cost management.

The Internet has put forward higher requirements for fine management. At the same time, with the interconnection and intercommunication between enterprises, and enterprises and environment, fine management is no longer limited to inside of the enterprise, but is extended to the whole supply chain.

Management accounting is an important tool for meticulous management and value creation, which has become the consensus of the industry. Through the analysis of the data model of management accounting, the Internet accelerates the deep integration of Finance and business, and strengthens the internal control and liquidity management in the process of integration. Based on the responsibility center accounting, the "small data" of the enterprise and "big data" of the Internet, the connotation of internal management report will be further enriched, and the maximization of the value of management accounting is possible.

\subsection{Management Accounting Improves Data Value. Big Data Provides Support for Benchmarking Management and Internal Reporting.}

One of the important functions of management accounting is to help managers make correct decisions by making good use of relevant information to predict the future of enterprises. Taking a comprehensive budget as an example, in the past, because of the limitations of records, storage and analysis tools, the overall budget of each enterprise is mostly limited to the internal data and historical data of the enterprise itself, and even the internal data of the enterprise is fragmented, it can not meet the standards of the same industry and the advanced enterprises.

In the future, based on cloud computing and large data technology, management accounting improves the value of the data. Large data provides support for the management of the standard and the internal report. It is possible to use data to realize the overall budget from the "three game" to "multiple game".

One of the essences of the Internet is the management of "de centralization", and customer centered decision making becomes the mainstream. This requires the use of the theory, tools and methods of management accounting to fundamentally improve the connotation and value of the internal reports provided by the enterprise, and to provide further roles to support the effectiveness of the whole and prompt decision-making.

\subsection{Management Accounting Can Promote The Upgrading of the Accounting Service Level.}

In the background of the "Internet plus", "Internet plus" has promoted the socialization division of labor, built a new modern accounting service system, and promoted accounting to realize the upgrading of the service level to adapt to the development of the market. Under the role of management accounting, the modern accounting service system has become increasingly rich. It provides more comprehensive, timely, relevant and reliable decision information and management information for the managers of the traditional enterprise owners and stakeholders, and improves the level of the accounting service.

In this process, the emphasis of the "upgrade version" of Chinese accounting services is to structure and develop management accounting. "Internet plus" brings new opportunities to the development of management accounting. Management accounting is an important part of modern enterprise management, which is playing a more and more important role in promoting the management level of Chinese enterprises and boosting the sustainable development of enterprises. In the times of "Internet plus", how to carry out effective resource allocation and timely performance evaluation of enterprises need analysis and planning of manage accounting personnel, which play the role of forecasting and planning.

Under the "Internet plus" environment, the importance of management accounting will be fully developed. Management accounting plays an increasingly important role in improving the ability of decision support, reducing cost, and increasing the competitiveness of enterprises.

Traditional accounting services provide only simple and standardized financial information. It is a mechanical system based on feedback, control and evaluation. The management accounting in the times of "Internet plus" will dynamically predict and plan operations and management according to the changes of the environment, provide real-time decision support, flexible optimization of 
resources, and continue to improve performance. At the same time,it will help to build financial analysis and forecast, financial strategic planning, capital market operation, comprehensive budget management system, comprehensive risk management system, reasonable business model and other professional systems, and promote the reform and upgrading of the whole accounting industry.

\subsection{Management Accounting Can Promote the Improvement of the Efficiency of Accounting Service.}

In the "Internet plus" times, enterprises operate efficiently, and also put forward higher requirements for the efficiency of accounting services. The traditional accounting reports accounting information in the extremely low efficiency, which reflects the economic business from the occurrence to the end of the filling voucher, including the recording in Ledgers and the preparation of the report. It takes 4 months for many enterprises to complete the annual financial statements. The compilation of quarterly reports takes 2 months. The compilation of monthly reports requires 10 days, which seriously blocks the improvement of the accounting service efficiency.

But with the market economy developing deeply, more and more enterprises are aware of the importance of instant financial statements than ever. Management accounting makes instant financial statements possible. The enterprise compile the timely financial statements makes accounting data have more meaningful. makes accounting change from post processing to processing, makes financial management alter from static management to dynamic management, accounting monitoring from discontinuous monitoring to continuous monitoring. At the same time, it breaks through the traditional accounting-period theory, so accounting information will play a more active role in enterprise management.

In the "Internet plus" times, the application of management accounting makes it possible. Through the data model analysis of management accounting, enterprises build financial sharing service platform to strengthen internal control, reduce risk, improve efficiency, and realize "cooperative business and centralized management".

Therefore, the data model analysis of the management accounting has established a information platform for the financial service allows the subsidiary to import the data into the system, and makes the pre-event promption, the event control and the post evaluation possible. The system can use the standardized system to perform various services, reduce the deviation and the possible dark box operation of various business units, and reduce the possible risks; It can automatically make the system to prompt the exception and the early warning through the data setting, and can make use of the openness of the model and system to establish the shared interfaces and platforms. The data users' needs are different, the financial statements required by the accounting standards and the management can be generated regularly through the model system.

Simultaneously, the group company can make use of the resources of the financial service platform to strengthen the financial monitoring of the subordinate institutions, and use the advanced information technology and network technology to make the centralized management possible through the network financial software.

In a word, the economic behavior of an enterprise is an important factor in the steady development of a country's economy, and its Internet transformation needs internal fine management. Meanwhile, the very important tool and means of fine management are the transformation and upgrading of the accounting industry, which is the management accounting.

\section{References}

[1] J. Sun Guanghui, Several problems in "Internet +" Education, Liaoning education, China, 23 (2017) 94-95.

[2] J. E Shengyu, Tang Yaxin, The development trend of the accounting industry in the "Internet +" era, Private technology, China, 11 (2017) 135-135.

[3] Information on http://news.yesky.com. 